\section{Alta prevalencia de la infección por el virus de hepatitis B en la comunidad indígena Japreira, Estado Zulia, Venezuela}

\author{
High prevalence of hepatitis B infection in \\ Amerindians in Japreira, Zulia State, Venezuela
}

\begin{abstract}
The aim of this study was to determine the prevalence of hepatitis B virus (HBV) infection in the Japreira indigenous community, Venezuela, and its relationship to age and gender. An intentional, non-probabilistic sample of 149 individuals was selected from a total of 300 . All samples were studied for the presence of total HBV antibodies (total anti-HBc), and the positive samples were tested for HBV surface and " $e$ " antigens (HBsAg, $H B e A g$ ). Overall prevalence rates of total anti$H B c$ were $72.9 \%$ in females and $81.1 \%$ in males. The highest prevalence of HBsAg was observed in males 26-35 years of age. Only four of the 44 HBsAg carriers were positive for HBeAg. The results showed a high endemic $H B V$ infection rate and indicated that its spread begins at early ages. Sexual transmission may be the main route for spread of the virus. Crowding, close contact with bodily fluids, specific social practices, and features of the circulating viral strain among members of this community could be involved in the high chronicity observed in the Japreira indigenous community.
\end{abstract}

Hepatitis B Virus; South American Indians; Indigenous Health

\author{
Francisca Monsalve-Castillo 1 \\ José Manuel Echevarría 2 \\ Ricardo Atencio ${ }^{1}$ \\ Anais Suárez 1 \\ Jesús Estévez ${ }^{1}$ \\ Luciana Costa-León 1 \\ Pilar Montiel 1 \\ Tania Molero ${ }^{1}$ \\ Mariana Zambrano ${ }^{1}$
}

\section{Introducción}

La alta endemicidad por el virus de la hepatitis B (VHB) que presentan diversos grupos indígenas de América del Sur 1,2,3,4,5,6 constituye un serio problema de salud pública. La prevalencia encontrada en la Amazonia Peruana es $64,3 \%$ (antiHBc total), de 9,4\% (HBsAg) 1, de 98\% (anti-HBc total) y entre $14-54 \%$ (HBsAg) en los indígenas Waorani de Ecuador 2. En Brasil la prevalencia está entre el 15,4-54,5\% (anti-HBc total) y del 3,49,7\% para el HBsAg 3,4. En los indígenas Yanomami del Estado Amazonas, Venezuela, alcanza un $68,4 \%$ y $17,3 \%$ entre los Piaroa 5 . En las etnias Yucpa y Bari de la Sierra de Perijá, se ubica por encima del $60 \% 6$.

Los indígenas Japreira comprenden un subgrupo de la etnia Yucpa. Son por naturaleza endogámicos, permitiéndose las relaciones sexuales entre familia, las cuales se inician a temprana edad. No utilizan tatuajes, perforaciones en piel, ni otra práctica similar. Una costumbre particular es la masticación de los alimentos por la madre antes de dárselos a sus infantes. Habitan en viviendas de un solo ambiente (varias familias), construidas en paja y piso de tierra, carecen de servicios básicos en salud, agua potable, luz, y correcta disposición de aguas negras. Sus ingresos económicos dependen de trabajos como peones en haciendas cercanas.

En base a la alta endemicidad presente en otras comunidades indígenas del ámbito latino- 
americano, este estudio persigue como objetivo conocer la prevalencia de la infección por el VHB en la comunidad indígena Japreira y determinar las pautas de su adquisición en función de la edad y sexo.

\section{Métodos}

Se analizaron 149 muestras de un total de 300 individuos por muestreo no probabilístico intencional. Los criterios de inclusión contemplaron: ser miembro de la comunidad indígena Japreira, mayor de 5 años, y presentarse voluntariamente a la toma de la muestra. La Sierra de Perijá se caracteriza por su entorno natural que combina una rica diversidad de ecosistemas. Las precipitaciones son abundantes $(1.500-2.400 \mathrm{~mm})$, las temperaturas oscilan entre $13^{\circ} \mathrm{C}$ a $30^{\circ} \mathrm{C}$. Cumpliendo con las normas de ética establecidas en los principios de la Declaración de Helsin$k i$, revisados en octubre del año 2000, y tras ser presentado el proyecto al Comité de Ética de la Facultad de Medicina, Universidad del Zulia, se obtuvo el consentimiento voluntario de los miembros de la comunidad para la realización de este estudio. Se extrajo por punción venosa $8 \mathrm{~mL}$ de sangre, en tubos sin anticoagulante para obtención de suero, conservándose a $-20^{\circ} \mathrm{C}$ hasta su procesamiento en el Laboratorio Regional de Referencia Virológica (Maracaibo, Venezuela). La determinación de anti-HBc total se realizó mediante un método comercial de enzimoinmunoanálisis (EIA) competitivo (DIMA Diagnostika mbH, Göttingen, Alemania). En toda muestra positiva para ese marcador se estudió la presencia del HBsAg y "e" del VHB
(HBeAg) mediante sendos métodos de EIA (DIMA Diagnostika). Los datos se analizaron mediante los análisis de chi-cuadrado y exacto de Fisher, según correspondiera. Para la correlación entre las variables estudiadas se utilizó el análisis de correlación de Spearman. Se utilizó como índice de confianza el 95\%, considerándose toda probabilidad menor de 0,05 como significativa.

\section{Resultados}

La Tabla 1 resume los resultados obtenidos en las 149 muestras en función de la edad y sexo de los sujetos estudiados. El anti-HBc total fue positivo en 116 muestras $(72,9 \%$ en el sexo femenino; $81,1 \%$ en el sexo masculino), y el HBsAg en $44(16,9 \%$ en el sexo femenino; $37,8 \%$ en el masculino). Sólo en el 6,8\% de las 44 muestras positivas para HBsAg pudo detectarse la presencia del HBeAg.

La prevalencia de anti-HBc total es superior al 50\% entre los sujetos menores de 16 años, y crece progresivamente en relación a la edad, a excepción de lo observado en el grupo de adultos entre 36-45 años, hasta alcanzar el 100\% entre los sujetos de mayor edad. La prevalencia de HBsAg muestra un pico $(61,1 \%)$ en adultos del sexo masculino entre los 26-35 años, descendiendo hasta alcanzar un mínimo entre los adultos mayores de 65 años.

\section{Discusión}

La prevalencia de anti-HBc total obtenida en la comunidad indígena Japreira en los sexos feme-

Prevalencia de anti-HBc total e incidencia de portadores de HBsAg por grupo de edad y sexo en indígenas de la comunidad Japreira, Sierra de Perijá, Venezuela. Presencia de $\mathrm{HBeAg}$ en las muestras positivas para $\mathrm{HbsAg}$

\begin{tabular}{|c|c|c|c|c|c|c|c|c|}
\hline \multirow{2}{*}{$\begin{array}{l}\text { Grupos de } \\
\text { edad (años) }\end{array}$} & \multicolumn{2}{|c|}{$\mathbf{n}$} & \multicolumn{2}{|c|}{ Prevalencia de anti-HBc } & \multicolumn{2}{|c|}{ Portadores de HBsAg } & \multicolumn{2}{|c|}{ Presencia de $\mathrm{HBeAg}$} \\
\hline & Femenino & Masculino & Femenino (\%) & Masculino (\%) & Femenino (\%) & Masculino (\%) & Femenino (\%) & Masculino (\%) \\
\hline $5-15$ & 18 & 24 & $9(50,0)$ & $14(58,3)$ & $5(27,8)$ & $5(20,8)$ & 4 * $(22,2)$ & $0(0,0)$ \\
\hline $16-25$ & 13 & 27 & $11(84,6)$ & $24(85,7)$ & $4(30,8)$ & $11(40,7)$ & $0(0,0)$ & $0(0,0)$ \\
\hline $26-35$ & 8 & 18 & $7(87,5)$ & $17(89,5)$ & $0(0,0)$ & $11 \star \star(61,1)$ & $0(0,0)$ & $0(0,0)$ \\
\hline $36-45$ & 9 & 8 & $6(66,7)$ & $6(75,0)$ & $1(11,1)$ & $3(34,5)$ & $0(0,0)$ & $0(0,0)$ \\
\hline $46-65$ & 8 & 9 & $7(87,5)$ & $8(100,0)$ & $0(0,0)$ & $3(33,3)$ & $0(0,0)$ & $0(0,0)$ \\
\hline$>65$ & 3 & 4 & $3(100,0)$ & $4(100,0)$ & $0(0,0)$ & $1(25,0)$ & $0(0,0)$ & $0(0,0)$ \\
\hline Total & 59 & 90 & $43(72,9)$ & $73(81,1)$ & $10(16,9)$ & $34(37,8)$ & $4(6,8)$ & $0(0,0)$ \\
\hline
\end{tabular}

* Diferente del sexo masculino del mismo grupo de edad $(p<0,05)$;

** Diferente del grupo femenino del mismo grupo de edad ( $p<0,01)$ y del grupo masculino de 5-15 años $(p<0,05)$ 
nino $(72,9 \%)$ y masculino $(81,1 \%)$, es superior a la indicada en otras etnias indígenas del territorio venezolano ${ }^{5,6}$. La prevalencia de HBsAg presente en el sexo masculino alcanza un elevado porcentaje $(61,1 \%)$ en el grupo de edad de $26-35$ años, a diferencia de sus congéneres femeninos, de la misma edad. El factor involucrado en dichos resultados podría ser la adquisición por vía sexual. Tanto hombres como mujeres de esta comunidad inician su actividad sexual a temprana edad. Los hombres, en búsqueda de mejores condiciones económicas, comienzan además a migrar a haciendas o comunidades urbanas vecinas; esta migración implica un mayor contacto con poblaciones foráneas, entre ellas trabajadoras sexuales que prestan sus servicios en esta región, sin control sanitario alguno. En las mujeres la prevalencia del anti-HBc sería producto de las relaciones sexuales con los hombres de su propia comunidad, los cuales han adquirido previamente la infección fuera de su entorno. La presencia del HBeAg en el sexo femenino en edades entre 5-15 confirmaría lo expuesto.

En las etnias Yuki y Parakaná, en Bolivia 7 y Brasil 8, la prevalencia de anti-HBc total indica que la adquisición de la infección comienza a temprana edad, alcanzando un alto porcentaje en la población antes de la adolescencia. Por primera vez, una comunidad indígena de América del Sur, ajena a la cuenca amazónica muestra una situación similar, cuyo contexto natural y cultural es diferente a las etnias mencionadas.

La persistencia del HBsAg en los hombres, a diferencia de las mujeres, radicaría en la mayor exposición de estos individuos a infecciones de transmisión sexual (ITS), como sífilis y herpes, adquiridas con parejas ajenas a su entorno comunitario. Las ITS pueden ser un factor predisponente en la adquisición del VHB 9. La elevada prevalencia de portadores de HBsAg entre los sujetos menores de 16 años de edad sugiere que la transmisión vertical podría jugar un papel epidemiológico importante, no obstante, los resultados obtenidos de la detección de HBeAg no respaldan esta interpretación, sugiriendo otras posibles rutas de transmisión. En estudio realizado, en el cual la prevalencia del HBsAg ha sido particularmente elevada en la población menor de 15 años, considera como factor importante en la transmisión y diseminación del virus, la relación intrafamiliar 10; el contacto madre-hijo durante los años siguientes al nacimiento aumenta considerablemente el riesgo a adquirir la infección. El hacinamiento, el compartir objetos de uso personal, el contacto intercorpóreo con fluidos biológicos, entre otros, serían posibles rutas de transmisión. La mayoría de los niños de la comunidad Japreira presentan lesiones en la piel, productos de picadas o lesiones producidas por diversas infecciones, la transferencia de secreciones corporales de adultos infectados por el VHB hacia estas lesiones potenciarían la transmisión del virus. Otra posible ruta de transmisión a considerar sería la práctica social observada en las madres, quienes mastican los alimentos antes de dárselos a consumir a sus infantes, es sabido que la saliva es un fluido importante en la transmisión del virus 1.

En América Latina el genotipo F del VHB es el más prevalente, acercándose al $100 \%$ en la mayoría de las comunidades indígenas estudiadas 11,12. Estudio realizado en portadores crónicos de la comunidad Japreira que presentan un subgenotipo específico (F2b), diferente del detectado en portadores de otras comunidades Yucpa de la región (F3) 13. La alta tasa de cronificación por el VHB entre los Japreira podría responder, en parte, a factores asociados a las características de la cepa de virus que circula entre ellos. 


\section{Resumen}

A fin de conocer la prevalencia de la infección por el virus de hepatitis $B(V H B)$ en la comunidad indigena Japreira, Venezuela, y determinar las pautas de su adquisición en función de la edad y sexo, se seleccionaron 149 individuos de un total de 300. Se detectó por métodos serológicos la presencia de anticuerpos totales del VHB (anti-HBc total), y en las positivas se investigó la presencia del antígeno de superficie (HBsAg) y del antígeno " $e$ " del VHB (HBeAg). La prevalencia de anti-HBc total fue de 72,9\% en el sexo femenino y $81,1 \%$ en el masculino, la prevalencia de HBsAg fue elevada $(61,1 \%)$ en el sexo masculino, sólo cuatro de los portadores de HBsAg fueron positivos para HBeAg. Los resultados obtenidos indican un grado elevado de endemia para esta infección y que su diseminación comienza a temprana edad. El factor involucrado en la adquisición y diseminación del virus seria la vía sexual. Hacinamiento, contacto intercorpóreo con fluidos biológicos, prácticas sociales, y características de la cepa viral circulante podrían estar involucradas en la alta cronicidad observada en la comunidad indígena Japreira.

Virus de la Hepatitis B; Indios Sudamericanos; Salud Indigena

\section{Referencias}

1. Cabezas C, Suárez M, Romero GC, Carrillo CP, García MP, Reátegui JS, et al. Hiperendemicidad de hepatitis viral B Delta en pueblos indígenas de la Amazonia peruana. Rev Peru Med Exp Salud Pública 2006; 23:114-22.

2. Stephen RM, Kelley PM, Kenneth CH, Douce R, Smalligan RD, Watts DM, et al. An outbreak of fulminant hepatitis Delta in the Waorani, an indigenous people of the Amazon basin of Ecuador. Am J Trop Med Hyg 2000; 63:209-13.

3. Braga WS, Brasil LM, Souza RA, Castillo MC, Fonseca JC. The occurrence of hepatitis B and Delta virus infection within seven Amerindian ethnic groups in the Brazilian western Amazon. Rev Soc Bras Med Trop 2001; 34:349-55.

4. Ferreira A, Greca D, Tavares E, Moriya Y, Spelling F, Boeira M. Seroepidemiology of hepatitis B na C in Kaingang indians in the South of Brazil. Rev Panam Salud Pública 2006; 20:230-5.

5. Cardona N, Garzazo D, Loureiro C, González K, García D, Pacheco M, et al. Dificultades para el diagnóstico serológico de las hepatitis virales $\mathrm{B}$ y C en población indígena venezolana. In: Anales del VIII Congreso Venezolano de Microbiología. Caracas: Sociedad Venezolana de Microbiología; 2004. p. 1-7.

6. Blitz L, Monsalve F, Atencio R, Monzon M, Favorov $\mathrm{M}$, Fields H, et al. Serologic survey of viral hepatitis markers among the Yucpa amerindian from western Venezuela. Ann Trop Med Parasitol 1996; 90:655-7.

\section{Colaboradores}

F. Monsalve-Castillo participó en el diseño, búsqueda bibliográfica, análisis y preparación del manuscrito. J. M. Echevarria contribuyó en el análisis crítico, discusión de los resultados, revisión y preparación del manuscrito. A. Suárez participó de la toma de muestra, discusión de los resultados y revisión del manuscrito. R. Atencio, J. Estévez, P. Montiel, M. Zambrano y T. Molero contribuyeron en la toma de muestra, logística de jornadas, procesamiento de muestras, revisión y acuerdo del manuscrito. L. Costa-León participó en la revisión y acuerdo del manuscrito.

\section{Agradecimientos}

La presente investigación contó con el apoyo económico del Consejo de Desarrollo Científico y Humanístico de la Universidad del Zulia (CONDES).
7. León P, Venegas E, Bengoechea L, Rojas E, López J, Elola C. Prevalencia de las infecciones por virus de las hepatitis B, C, D y E en Bolivia. Rev Panam Salud Pública 1999; 5:144-52.

8. Soares M, Menezes R, Martins S, Bensabath G. Epidemiología dos virus das hepatitis B, C e D na tribo indígena Parakanã Amazônia Oriental Brasileira. Bol Of Sanit Panam 1994; 117:124-33.

9. Ghanaat J, Sadeghian A, Ghazvini K, Nassiri MR. Prevalence and risk factors for hepatitis B virus infections among STD patients in northeast region of Iran. Med Sci Monit 2003; 9:CR91-4.

10. Melo LB, Fonseca JC, Souza RB, Braga WS, Toledo LM. Prevalence of hepatitis B virus markers within household contacts in the State of Amazonas. Rev Soc Bras Med Trop 2003; 36:565-70.

11. Nakano T, Lu L, Hu X, Mikozami M, Orito E, Shapiro C, et al. Characterization of hepatitis B virus genotypes among Yucpa Indians in Venezuela. J Gen Virol 2001; 82:359-65.

12. Quintero A, Uzcategui N, Loureiro CL, Villegas L, Illarramendi X, Guevara ME, et al. Hepatitis Delta Virus genotypes I and III circulate associated with hepatitis B virus genotype F in Venezuela. J Med Virol 2001; 64:356-9.

13. Devesa M, Pujol F. Hepatitis B genetic diversity in Latin American. Virus Res 2007; 127:177-84.

Recibido el 01/Ago/2007

Versión final presentada el 29/Nov/2007 Aprobado el 31/Ene/2008 